Uma proposta diferenciada para o ensino e aprendizagem da matemática na educação básica

Gabriel Xavier Santos

\title{
Resumo
}

O presente trabalho tem como finalidade relatar a experiência realizada através do projeto de extensão "Matemáticando", que possui como objetivo promover a interação de alunos do ensino fundamental e médio com a Matemática, por meio da utilização de materiais manipulativos, jogos matemáticos interativos e propostas diferenciadas para resolução de problemas. Deste modo, apresentamos as práticas alternativas para o ensino de Geometria e Trigonometria, que fazem parte do projeto, identificando diferentes propostas de organização de atividades de ensino na tentativa de criar um espaço para experimentação de novas práticas com a proposta de desmitificar a ideia de que Matemática é uma matéria difícil. Assim, evidenciamos parte das atividades que proporcionaram de maneira criativa a elaboração de atividades por parte dos professores e dos licenciandos envolvidos. "Matemáticando" fez parte do programa de extensão comunitário "UniverCidades" da Universidade Estadual do Sudoeste da Bahia.

Palavras chave: Material manipulativo, Educação interativa, Matemática. 


\section{Objetivos da Atividade}

A Matemática é uma disciplina essencial para o indivíduo compreender o mundo e resolver diversas situações do seu cotidiano, porém, apresenta altos índices de reprovação nas escolas de ensino básico do nosso país e, às vezes, rejeitada pelo interesse de muitos alunos. Para D’Ambrosio (1999):

As ideias matemáticas comparecem em toda a evolução da humanidade, definindo estratégias de ação para lidar com o ambiente, criando e desenhando instrumentos para esse fim, e buscando explicações sobre os fatos e fenômenos da natureza e para a própria existência. Em todos os momentos da história e em todas as civilizações, as ideias matemáticas estão presentes em todas as formas de fazer e de saber (p. 97).

A Matemática na vida é utilizada, desde as mais simples tarefas do dia a dia como também nas mais complexas, gera um conforto para além da escola como também em diversas de suas atividades no cotidiano, mas infelizmente poucos são os alunos que possuem essa percepção, nem sempre isso é transmitido para os estudantes. Segundo Nunes e Bryant (1997),

sem matemática eles ficarão desconfortáveis não apenas na escola, mas em uma grande parte de suas atividades cotidianas: quando partilham bem com seus amigos, planejam gastar suas mesadas, discutem sobre velocidade e distâncias, viajam e têm de lidar com o mundo do dinheiro, de compras e vendas, hipotecas e apólices de seguro, precisam de habilidades matemáticas. (p.63)

Pode-se destacar um exemplo disso à famosa frase e a mais dita nas aulas de Matemática: "Para que vou usar isso na minha vida?". E na maioria das vezes o discurso do professor obtido como resposta, não satisfaz o educando.

Em algumas das escolas do nosso país os alunos são condicionados aos cálculos mecânicos para saberem fórmulas que respondam as questões de provas e exames classificatórios, assim, não aprendendo os inúmeros caminhos, segredos e curiosidades que a Matemática pode proporcionar.

Com o intuito de transformar as aulas de Matemática, pensamos em um meio de trazer dinâmica e prática para alguns assuntos, utilizando as tendências de ensino das matemáticas. Para isso elaboramos o projeto "Matemáticando".

\section{O Programa "UniverCidades"}

O "UniverCidades" foi um programa de extensão da Pró-Reitoria de Extensão e Assuntos Comunitários (PROEX), da Universidade Estadual do Sudoeste da Bahia (UESB), que foi criado com o intuito de intensificar as ações extensionistas levando um conjunto de ações desenvolvidas pelos discentes, aos municípios do Sudoeste da Bahia, permitindo 
diálogo e interação entre a Universidade e os demais segmentos sociais através de ações, como cursos, palestras, oficinas, treinamentos e capacitação, atividades desportivas e culturais.

Os eventos são planejados de acordo com as áreas temáticas comunicação social, tecnologia e produção, meio ambiente, cultura, direitos humanos e justiça, trabalho, educação e saúde, que em 2013 alcançou mais de 5000 pessoas em 80 cidades da região. $\mathrm{O}$ programa é seletivo e atualmente por conta da retenção de custos, está inativo, no último ano que funcionou em 2015 foram 196 graduandos participantes e 46 projetos aprovados que com muitas dificuldades nem todos foram executados. A seguir falaremos mais detalhadamente sobre "Matemáticando".

\section{Procedimentos}

O Projeto "Matemáticando" tem a intenção de possibilitar uma reflexão sobre a metodologia mais dinâmica e interativa com os estudantes do ensino básico nas escolas públicas, uma aprendizagem como atividade contínua. Tem-se a utilização da própria prática como objeto de reflexão e de aprimoramento na construção de conhecimentos.

Na verdade, aprender Matemática não é tarefa fácil, mas é necessário criar maneiras de inovar o ensino mostrando a real importância dessa área do conhecimento no dia-a-dia. A utilização de materiais concretos e atividades lúdicas, pode estimular o aluno a manipulação e total participação nas atividades, gerando maior compreensão do assunto abordado. $\mathrm{O}$ projeto foi subdividido em quatro atividades lúdicas que utilizam materiais concretos e o computador.

A primeira atividade propõe a aplicação das Noções Trigonométricas no Triângulo Retângulo, com ideias de semelhança e relações métricas do triângulo. Esta atividade tem grande importância, pois muitos alunos sentem dificuldades de trabalhar com a trigonometria, como a atividade utiliza materiais manipulativos, logo os mesmos terão mais condições de envolver com o assunto.

A segunda atividade é a Operações de Frações com o Hexágono, esta tem a finalidade de visualizar as intervenções de frações, fazendo com que o aluno compreenda com mais facilidade. Primeiro o aluno confecciona o material, criando o hexágono inteiro e fracionado com 1/2, 1/3 e 1/6 do mesmo. Logo após é respondida uma lista na qual os alunos resolvem as operações utilizando somente as peças construídas. (figura 1) 
Figura 1: Operações de Frações com o Hexágono.

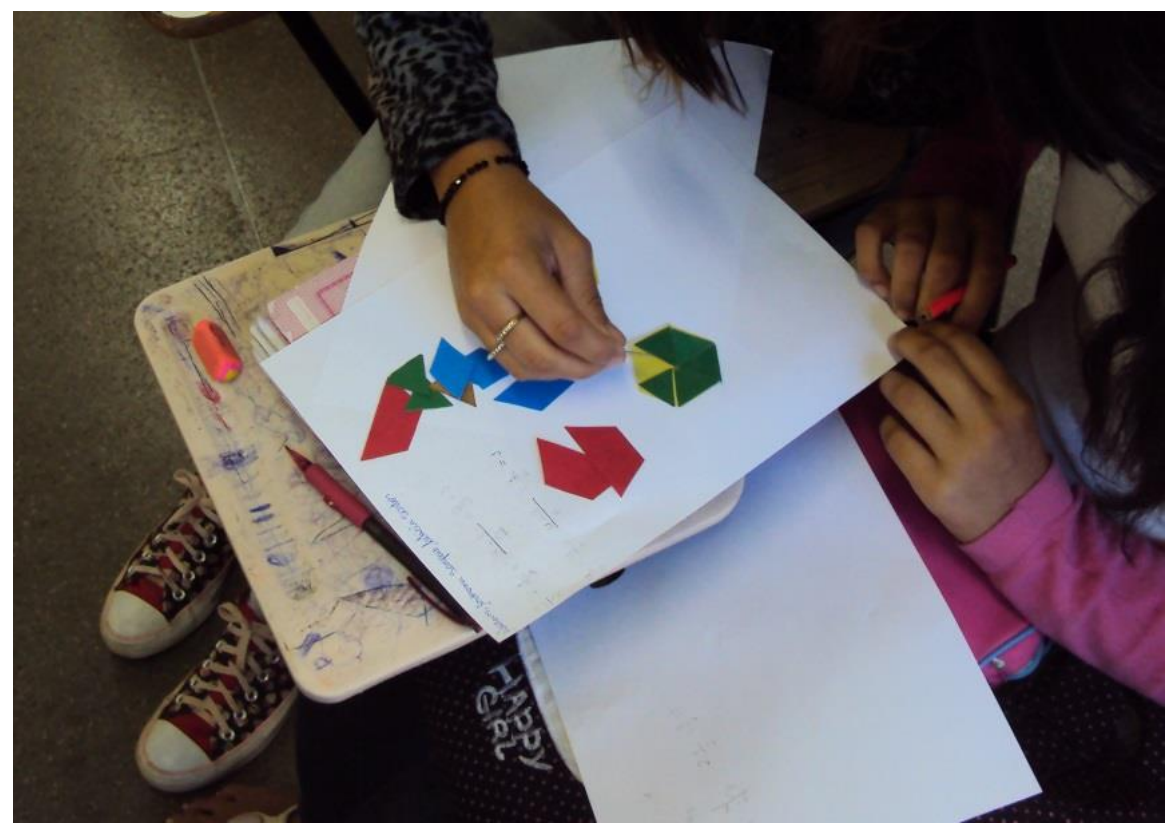

Arquivos do Autor

A terceira atividade é simples, pois os alunos compreendem o Teorema de Pitágoras, com demonstrações práticas a qual os mesmos confeccionam o material e passo a passo recortam quadrados de lado com 3, 4 e 5 centímetros, onde a partir daí, criam o triângulo retângulo sendo capaz de chegar à demonstração do teorema. (figura 2)

Figura 2: Demonstração do Teorema de Pitágoras.

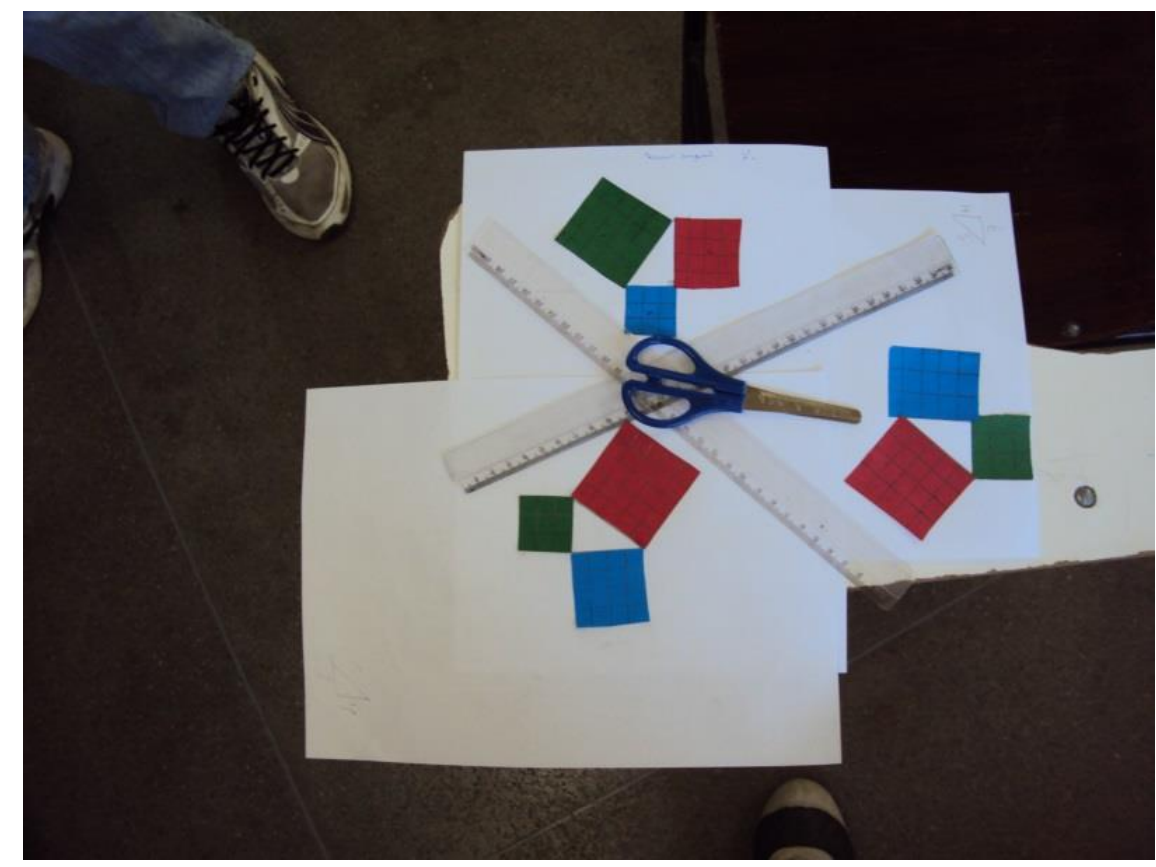

Arquivos do Autor

ISSN 2526-2882

$* 19 *$ 
A quarta atividade intitulada Explorando a Geometria Presente no Tangram com o Geogebra, onde o objetivo é explorar a Geometria presente no Tangram com o uso da tecnologia. Primeiramente, em sala de aula, os alunos trabalham construindo o Tangram passo a passo, manipulando os materiais e explorando a área de algumas peças. Posteriormente no software Geogebra, o aluno trabalha novamente a construção e exploração da geometria presente no Tangram, seguindo passo a passo as dicas e relacionando com a atividade anterior. Diante destas atividades, aumenta a capacidade de maior interatividade dos alunos com os assuntos abordados, fazendo com que ele seja o ator principal dos seus conhecimentos.

\section{Reflexões}

Por questões funcionais, não conseguimos executar o projeto através do programa "UniverCidades". Sendo assim resolvemos aplicar em um colégio público da cidade, pois gostaríamos de saber se os nossos objetivos seriam alcançados. Sendo assim aplicamos o projeto no Colégio Estadual Dr. Orlando Leite situado na região periférica da cidade de Vitória da Conquista, Bahia, Brasil. A turma escolhida foi do $2^{\mathrm{o}}$ ano do ensino médio matutino, constituída por 27 alunos com faixa etária de 14 a 16 anos. O Laboratório de Matemática da Universidade Estadual do Sudoeste da Bahia forneceu parte do material necessário para a execução, daí então foi possível aplicar o projeto. Em seguida relataremos duas das atividades aplicadas, pois foram as que nós tivemos os resultados mais gratificantes, sendo elas, Noções Trigonométricas no Triângulo Retângulo e Explorando a Geometria Presente no Tangram com o Geogebra, primeira e quarta atividade respectivamente.

\section{Noções Trigonométricas no Triângulo Retângulo}

Na atividade de Noções Trigonométricas no Triângulo Retângulo utilizamos quatro aulas de 50 minutos em dois dias distintos, totalizando 3 horas e 20 minutos. O objetivo foi trabalhar os conceitos básicos de trigonométricos, semelhança de triângulos e suas relações métricas.

Inicialmente apresentamos e trabalhamos as definições necessárias através de uma aula explicativa utilizando o quadro negro. Neste momento introduzimos as noções de triângulo retângulo (catetos, hipotenusa e ângulos) e posteriormente as razões trigonométricas (seno, cosseno e tangente), percebemos pela participação dos alunos que apresentavam dificuldades relacionadas aos conteúdos. Em seguida, com a turma organizada em trios, foi disponibilizado o material (cartolina, tesoura, esquadro, transferidor, cola, papel, compasso), bem como um questionário, o qual serviria para orientar a execução da atividade. Sendo assim, seguindo as orientações, os educandos recortaram três triângulos, os 
quais deveriam ser um grande, um médio e um pequeno, logo após teriam que relacionar as características e semelhanças dos triângulos construídos (figura 3).

Figura 3: Utilizando material manipulativo.

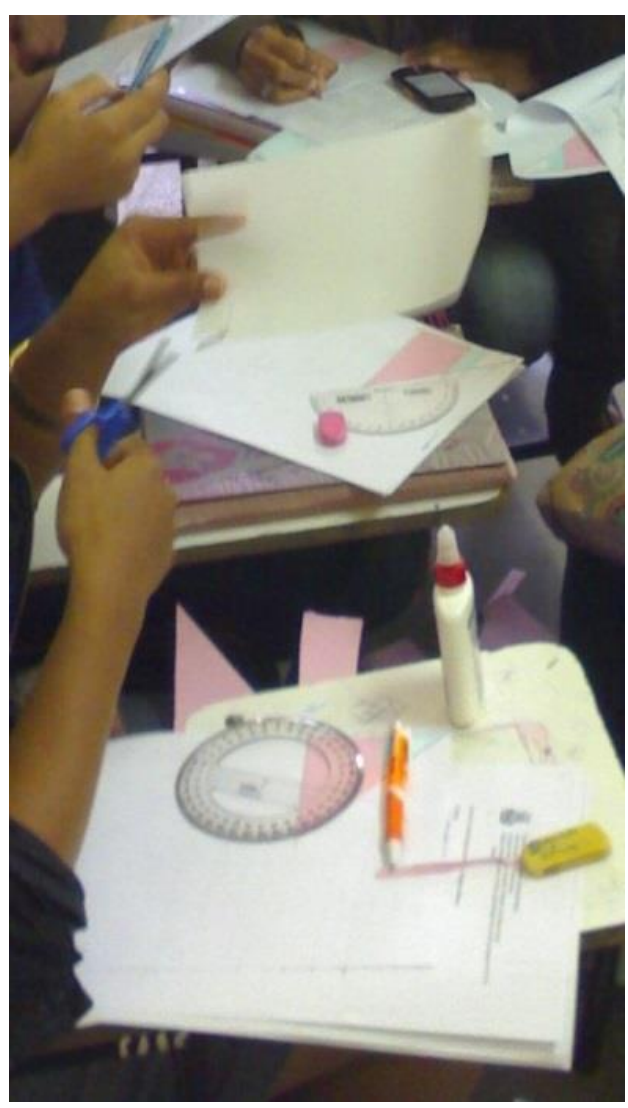

Arquivos do Autor

Percebemos que na execução, os alunos apresentaram dificuldades no uso do material, como por exemplo, o transferidor para fazer a medida dos ângulos, foi necessário a intervenção dos ministrantes. Após os triângulos construídos, foi solicitado que colassem os triângulos com o menor em cima do maior, no qual a medida do ângulo beta deveria ser comum a todos.

$\mathrm{Na}$ etapa seguinte eles deveriam responder as questões o qual encontravam as razões das medidas de seus triângulos, neste caso os resultados deveriam ser iguais, ou seja, com a mesma razão os triângulos seriam semelhantes. Em alguns grupos, as razões eram diferentes, logo a confecção dos triângulos não foi feita com os ângulos certos, já ouve grupos que tiveram o mesmo resultado, e assim, compreenderam um dos casos de semelhança de triângulos (AA - Ângulo, Ângulo).

A última parte do questionário os alunos tinham que encontrar os valores de seno, cosseno e tangente e relacionar estes valores entre todos os triângulos semelhantes e entre os 
ângulos do mesmo triângulo, tirando uma conclusão explicativa dessas características, logo saberíamos mesmo se compreenderam o que queríamos passar.

Seguindo a mesma linha de pensamento que Ávila (1995) quando afirma que "a Resolução de Problemas enquanto metodologia deve se preocupar mais com o processo do que com a solução do problema”. E enxergando que o erro faz parte do aprendizado, apresentamos a proposta, entregamos o questionário juntamente com o material e tirávamos as dúvidas indo de grupo em grupo.

Dos 25 alunos presentes na atividade apenas um que entregou a atividade em branco no primeiro dia e não foi no segundo e outros quatro alunos que não conciliaram à teoria a prática, pois sabiam como se definia a semelhança de triângulos, mas na hora de desenhar, cortar e colar fizeram de maneira que não foi possível obter os resultados desejados, não pediram a nossa ajuda e nós não identificamos o erro durante a execução, foram os estudantes que não suprimos a defasagem, a prova disso foram os diversos relatórios escritos e motivadores que tivemos ao final da oficina.

ESTUDANTE A: "A aula foi muito interessante pois aprendemos um assunto difícil de um jeito diferente aprendi muito sobre os triângulos."

ESTUDANTE B: "Concluir que o estágio dos meninos da UESB foi muito 'favorecente' ao nosso aprendizado eles ensinam muito bem. Tivemos uma maneira muito legal de aprender Geometria, eu sou péssima no mínimo 'aprendir' alguma coisa que possa usar em sala de aula."

Confirmando uma situação que foi consenso entre a turma, no próximo relato o aluno trata da dificuldade da $3^{\circ}$ etapa, quando a diferencia da $2^{\circ}$ era apenas a notação ao invés de cateto oposto sobre adjacente se tinha tangente e assim com o seno e o cosseno.

ESTUDANTE C: "Essa atividade foi bastante proveitosa pois adquiri um pouco mais de conhecimento sobre Geometria, porém tive algumas dificuldades principalmente na terceira etapa do exercício. Agradeço aos estudantes da uesb pela a boa vontade de nos ensinar."

\section{Explorando a Geometria Presente no Tangram com o Geogebra}

Atividade a seguir, foi dividida em dois momentos, cada um deles foi utilizado duas aulas geminadas de 50 minutos em dois dias distintos, totalizando 3 horas e 20 minutos. No primeiro momento foi passada um pouco de umas das várias histórias relacionadas ao surgimento do Tangram, logo após solicitamos aos alunos a construção do seu próprio Tangram com o material manipulativo, sempre questionando a definição, a cada passo executado, a cada nova figura formada. Ao perguntarmos "que figura é essa?" Todos respondiam, mas quando se perguntava o porquê, a definição, apenas um aluno sempre se arriscava a responder, aluno este que se destacou em todas as nossas atividades. Sendo 
assim, começamos a direcionar algumas perguntas e sempre dando algumas dicas, fazendo com que os outros estudantes também participassem.

Após a confecção do Tangram, pedimos para que fizessem o cálculo das áreas e perímetros das peças encontradas, houve uma imensa dificuldade, após tirarmos algumas dúvidas pedimos para que alguns alunos respondessem no quadro, o qual as diversas soluções obtidas para a mesma pergunta foi bem esclarecedor que existe diversas maneiras de se chegar ao mesmo resultado nas questões matemáticas.

No Segundo momento fizemos o uso da Tecnologia de Informação e Comunicação (TIC), em especial o software Geogebra para trabalhar a geometria presente no Tangram. Optamos por utilizar a TIC porque acreditamos na necessidade da inclusão digital do aluno quando se trata de softwares educacionais. E até mesmo pelo o que Hendres e Kaiber afirmam; "o uso do computador no ensino de Matemática é uma necessidade atual e deve, cada vez mais, ligar-se à rotina didática dos professores e à escola em geral.” (p. 26).

Depois de levarmos os alunos para o laboratório de informática que eles nunca tinham utilizado, mesmo aqueles que estudavam na unidade escolar desde o sexto ano, apresentamos o software Geogebra, o qual eles não conheciam. Após um breve tutorial sobre as funções das principais ferramentas iniciamos o passo a passo a construção do Tangram.

A última etapa deste trabalho, fazendo uso das ferramentas do Geogebra, foi possível explorar as definições e características das formas geométricas presentes no Tangram (área, perímetro, diagonal, bissetriz e altura) de forma mais dinâmica, as mesmas trabalhadas no momento anterior, assim foi perceptível a participação de mais alunos nos questionamentos. Trabalhamos também a razão entre as medidas das peças semelhantes. Um aluno logo questionou "Mentira, que toda essa facilidade aqui, foi aquele trabalhão de ontem". Isso fez com que nós questionássemos uma comparação entre o cálculo no Geogebra e o cálculo à mão, alguns ainda fizeram o cálculo utilizando a fórmula para ver se alcançaria o mesmo resultado.

\section{Considerações Finais}

Diante o que já foi exposto, é interessante ressaltar que a prática da Matemática com atividades lúdicas, pode ser usada como um recurso didático-metodológico que desperta interesse, atenção, curiosidade, motivação e agilidades no alunato, tornando assim uma aprendizagem expressiva e constatando também que o erro faz parte do aprendizado.

A necessidade de inovar a metodologia de ensino levando dinamismo e interatividade proporciona melhor reflexão e aprimoramento na construção de conhecimentos. O aluno é um ser capaz, que tem sede de conhecimento e possui vigor na aprendizagem, ele precisa de motivação e desafios para evoluir constantemente e não 
estagnar em uma etapa de sua aprendizagem. Concluísse que o diálogo e o método de ensino influencia na aprendizagem mudando o seu percentual de aproveitamento em sala de aula.

\section{Referência}

ÁVILA, G. Objetivos do Ensino da Matemática. São Paulo: SBM, 1995.

D’AMBROSIO, U. A história da matemática: questões historiográficas e políticas e reflexos na Educação Matemática. In: BICUDO, M. A. V.(org.). Pesquisa em Educação Matemática: concepções e perspectivas. São Paulo: UNESP, 1999. p. 97-115.

HENDRES, C. A. KAIBER, C. T. A utilização da informática como recurso didático nas aulas de Matemática. Acta Sientiae Revista de Ciências Naturais. Vol. 7, n. 1, p. 25-38, Jan.Jul./2005.

NUNES, T. ; BRYANT, P. Crianças fazendo matemática. Porto Alegre: Artes Médicas, 1997.

\section{Biografia Resumida}

Gabriel Xavier Santos. Graduando de Licenciatura em Matemática Universidade Estadual do Sudoeste da Bahia - UESB/Campus de Vitória da Conquista.

link do Lattes: http://lattes.cnpq.br/3531604647286146

e-mail: gabrielxavier.mat@gmail.com 